\title{
O ESTRANHAMENTO DO BANAL: A POÉTICA MAGRITTEANA SOB UM OLHAR PSICANALÍTICO
}

\author{
Alan Ricardo Floriano Bigeli \\ Universidade Estadual Paulista Júlio de Mesquita (UNESP), Assis, SP, Brasil \\ Gustavo Henrique Dionisio \\ Universidade Estadual Paulista Júlio de Mesquita (UNESP), Assis, SP, Brasil
}

\begin{abstract}
Resumo
O presente artigo pretende construir possíveis relações entre a psicanálise e algumas das obras mais inquietantes de René Magritte (1898 - 1967), mantendo consonância com a curadoria de uma exposição sobre o artista, chamada "Magritte: The Mystery of the Ordinary". Para tanto, além de nos debruçarmos sobre materiais de comentadores e críticos da obra do pintor, investigamos também os textos produzidos pelo próprio Magritte, nos quais o pintor versa sobre conceitos fundamentais para a compreensão de seu pensamento artístico: emoção estética, poética, mistérios do cotidiano, estranhamento (ressoante ao Umheimlich freudiano). Tivemos aqui o cuidado de manter alguma distância de interpretações superficiais e reducionistas, que simplesmente aplicassem a psicanálise à obra de arte. Portanto, buscamos construir uma leitura crítica, atenta aos detalhes e atravessamentos que percorrem as obras de arte, evidenciando as implicações ali presentes e propondo aproximações entre a obra de Magritte e a teoria psicanalítica.
\end{abstract}

Palavras-chave: Psicanálise; Arte; Reflexões Estéticas.

\section{THE STRANGENESS OF COMMONPLACE: MAGRITTE'S POETICS BENEATH A PSYCHOANALYTICAL GLANCE}

\begin{abstract}
This article aims to build possible relationships between psychoanalysis and some of the most puzzling works of René Magritte (1898 - 1967), keeping consistent with the curating of an exhibition called "Magritte: The Mystery of the Ordinary". Thus, we dedicated to reading materials of commentators and critics of the painter's work, we also investigated the texts produced by Magritte himself, in which the painter introduces some key-concepts for the understanding of his artistic thinking: aesthetic emotion, poetics, mysteries of the ordinary, uncanny (resounding the Freudian's Umheimlich). Thereby, we were careful to not produce superficial and reductionist interpretations, which only implement psychoanalysis to the art. Therefore, we aimed to produce a critical interpretation, attentive to details of art works, demonstrating the implications present there and showing possible links between the work of Magritte and psychoanalytic theory.
\end{abstract}

Keywords: Psychoanalysis; Art; Aesthetic Reflections. 


\title{
LA EXTRAÑEZA DE LO BANAL: LA POÉTICA MAGRITTEANA BAJO UNA PERSPECTIVA PSICOANALÍTICA
}

\begin{abstract}
Resumen
Este artículo tiene como objetivo construir posibles relaciones entre psicoanálisis y algunas de las obras más inquietantes de René Magritte (1898 - 1967), manteniendo consonancia con la curaduría de una exposición, llamada "Magritte: The Mystery of the Ordinary". Más allá de las lecturas de materiales de comentaristas y críticos de la obra del pintor, igualmente fueran investigados los textos producidos por el propio Magritte, en que el pintor escribe sobre los conceptos fundamentales para la comprensión de su pensamiento artístico: emoción estética, poética, misterios de lo cotidiano, extrañamiento (en referencia a el Umheimlich freudiano). Aquí nos interesa mantener cierta distancia de las interpretaciones superficiales y reduccionistas que simplemente implementan el psicoanálisis a la obra de arte. Por lo tanto, buscamos construir una lectura crítica, atenta a los detalles presentes en las obras de arte, demostrando las implicaciones y proponiendo vínculos entre la obra de Magritte y la teoría psicoanalítica.
\end{abstract}

Palabras clave: Psicoanálisis; Arte; Reflexiones Estéticas.

\section{INTRODUÇÃO}

\section{Apontamentos contextuais}

Não resta dúvida que René Magritte (1898 - 1967) inscreveu seu nome na história mundial da arte; em seus primeiros anos como pintor, teve fortes influências do Abstracionismo, do Futurismo, do Cubismo e do Dadaísmo, sendo que este último deixou marcas significativas em sua "ideologia de vida", vistas através do teor irônico encontrado em seu trabalho (Gablik, 1985). Contudo, foi dentro da vanguarda surrealista que o pintor se consagraria, quando passou a frequentar o círculo francês, exercendo forte participação nas produções artísticas e literárias do movimento. Seu período na França não durou mais que três anos, e, após desavenças pessoais e ideológicas com Breton, volta para a Bélgica, onde continuou a carreira no conforto de seu país natal (Mensa, 2011). Para Magritte (2010), o movimento Surrealista:

[...] comporta para a humanidade um método e uma orientação de espírito, apropriados para aprofundar as investigações nos domínios ignorados ou depreciados e que, entretanto, interessam diretamente ao homem, o Surrealismo, enfim, reivindica para a vida desperta uma liberdade semelhante à que temos quando dormimos (Magritte, 2010, p. 67, tradução nossa).

O termo Surrealismo surge, pela primeira vez, no programa do balé Parade de Jean Cocteau em maio de 1917, escrito por Guillaume Apollinaire, no qual se lê que a "verdade artística resultante da combinação dos elementos do espetáculo era uma verdade além da realidade" (Bradley, 2001, p. 6). Em junho do mesmo ano o termo sur-realisme volta a aparecer, porém desta vez durante o clímax de uma peça escrita pelo próprio Apollinaire, intitulada Las Mamelles de Tirésias (Ades, 1976).

Apesar de Apollinaire ter ditado somente o nome do movimento surrealista, e não atingir poeticamente seu "real espírito", André Breton 
(1924/1985), tendo um grande fascínio por sua obra, em seu primeiro Manifesto intitula, juntamente com Phillippe Soupault, o movimento artístico como Surrealismo, sendo este um "novo modo de expressão pura, agora à nossa disposição, e com o qual estávamos impacientes para beneficiar nossos amigos" (Breton, 1924/1985, p. 56).

Segundo Breton (1924/1985), fundamental ao Surrealismo era a premissa da palavra liberdade. Tal aclamação ao conceito se dá pelo "velho fanatismo humano" que essa palavra carrega, ainda mais quando relacionada à imaginação que, sendo assim, remete a Breton sua "única aspiração legítima" (Breton, 1924/1985, p. 35). A vanguarda surrealista, na busca por sua surrealidade, volta-se para as excrescências do familiar: "a casa tem um tumor: sua sacada. É esta que o surrealismo vai pintar"; em outras palavras, o Surrealismo debruça-se naquilo que transpassa a forma e o fechamento habitual da vida banal, resgatando a essência própria de cada coisa, somada à "incapacidade de lidar com o fato de que sua racionalidade é irracional" (Adorno, 2003, p. 140).

Desde os primeiríssimos passos do Surrealismo, segundo Walter Benjamin (1975), seus signatários buscavam modos de rompimento com certas práticas artísticas que retratavam aspectos muito bem determinados pelo fechamento da forma, caracterizando um rompimento "de dentro para fora", buscando uma prática de vida poética que seria levada até "os limites extremos do que era possível fazer-se." (Benjamin, 1975, p. 83). É válido, ainda, destacar a categorização definida por Breton (1924/1985) em seu Manifesto de 1924, no qual define com clareza, e "de uma vez por todas", aquilo a que se propõe tal vanguarda:

SURREALISMO: s.m. Automatismo psíquico puro pelo qual se propõe exprimir, seja verbalmente, seja por escrito, seja de qualquer outra maneira, o funcionamento real do pensamento. Ditado do pensamento, na ausência de todo controle exercido pela razão, fora de toda preocupação estética ou moral.

ENCICL. Filos. O Surrealismo repousa sobre a crença na realidade superior de certas formas de associações desprezadas antes dele, na onipotência do sonho, no desempenho desinteressado do pensamento. Tende a demolir definitivamente todos os outros mecanismos psíquicos, e a se substituir a eles na resolução dos principais problemas da vida. [...] (Breton, 1924/1985, p. 58).

André Breton (1924/1985) relata que a inspiração para a noção de automatismo surgiu através de uma frase aleatória que apareceu relutante em seu pensamento durante uma noite, enquanto o poeta tentava dormir. As palavras que constituíam essa frase eram aleatórias de tal modo que, ao apresentá-la em seu primeiro Manifesto, de 1924, sua memória as tornara obsoletas, mantendo, portanto, o foco voltado com mais intensidade à forma como essa frase lhe surgira - automática e involuntariamente - do que ao seu conteúdo. Com essas ideias e inspirado pela metodologia freudiana da livreassociação, Breton interessa-se pela concepção de como "a velocidade do 
pensamento não é superior à da palavra (escrita ou falada)" possibilitando assim a comunicação de seu pensamento, pode-se dizer, diretamente através da fala: um "pensamento falado" (Breton, 1924/1985, p. 54-55).

Nessa premissa, Magritte proporciona, através de sua obra, um convite para adentrar um mundo que, amparado na realidade inerente aos objetos, tal como nos é apresentada cotidianamente, reflete a relação, ou o distanciamento, que esses objetos têm com essas características intrínsecas à esfera do familiar. Através de provocações que mantêm seu ponto de partida na realidade aparente - correlatas às paradoxais relações que a simples subversão do ambiente costumeiro possam tomar - o artista provoca, através de imagens poéticas, o desconforto a um certo tipo de olhar que esteja fadado a enxergar a natureza tal como ela se apresenta (Magritte, 2009).

A concepção de seus trabalhos visuais dialoga com os pensamentos encontrados em seus textos, produzidos concomitantemente à evolução de sua técnica e temática enquanto artista. Utilizando-se de escritos, Magritte empregava palavras e frases em seus quadros, que para ele tinham o sentido igualmente comparável às suas imagens pintadas (Panek, 2006). Equiparando-se também a essa ideia, aparecem os títulos de seus quadros; palavra e imagem não se contrapõem, mas produzem mutuamente um sentimento singular e variável de acordo com a subjetividade de quem lance um olhar mais sensível à obra de arte.

\section{MÉTODO}

A representatividade de uma emoção estética

Para que Magritte produzisse seu trabalho artístico, era essencial a busca por um sentimento singular que empregasse tanto a subjetividade do pintor quanto a de quem observa a obra de arte, caracterizando assim uma provocação que deslocasse a realidade ordinária; Magritte chamava esse sentimento de emoção estética. O pintor belga defendia em seus textos que essa sensação única, atingida através de uma obra de arte, implica uma relação entre três instâncias: 1) o artista; 2) sua obra e; 3) seu espectador; com a finalidade de alcançar a realidade escondida nos objetos do cotidiano. Seria esse o real sentido de uma obra de arte segundo o pintor (Magritte, 2009).

Em suas investigações sobre objeto e representação, Magritte se ocupava em encontrar soluções para aquilo que julgava serem problemas da realidade. Nessa perspectiva, ele se dedicava a encontrar possíveis similitudes entre cada um dos objetos retratados, explorando a forma como estes se apresentavam, além de friccionar determinadas relações buscando sempre um sentido escondido por detrás daquilo que seus olhos viam. Ou seja, suas provocações vão de encontro ao conforto habitual do olhar, buscando justamente a relação 
contraditória que, misteriosamente, a natureza poderia revelar (Umland et al., 2013).

As pinturas de Magritte surgem, portanto, ancoradas nessa realidade que se apresentava de maneira mágica, na qual todos os objetos escondiam e mostravam algo ao mesmo tempo. Por meio da relação arte-pensamento, Magritte lançou seu olhar para essa realidade misteriosamente familiar. Seguindo essa premissa, a inspiração de suas obras aparecia vinculada ao seu pensamento, instância a qual o pintor atribuía extrema importância: todas as suas sensações, emoções e, acima de tudo, a inspiração provinham daí. Assim, Magritte encontrou mecanismos para dar visibilidade ao seu pensamento que foram traduzidos em imagens poéticas, culminando na construção de suas telas.

A intenção provocativa da obra magritteana aparece em vários âmbitos, mas principalmente quando o artista encontra o caminho de transformar suas reproduções pictóricas em poesias visíveis, que provocam e instigam o espectador a pensar a respeito dos mais variados temas que o cercam e que já se habituou a não questionar mais. Desse modo, Magritte pensava títulos para suas telas que buscassem sensações igualmente equiparáveis às apreensões possíveis de serem transmitidas por suas imagens (Panek, 2006; Magritte, 2009). Nessa perspectiva, optamos por elaborar um recorte de algumas obras presentes na gama escolhida pela curadoria da exposição Magritte: The Mystery of the Ordinary, de 2013. São obras que conseguem estabelecer, a nosso ver, ricas relações de proximidade com a teoria freudiana. Nesse sentido, tivemos a intenção de explorar ao máximo a contextualização dessas telas que constituem nosso corpus de pesquisa, seus processos de elaboração e construção, as temáticas utilizadas, a singularidade presente em suas representações, além de tecer comentários sobre o processo de criação de seus títulos e versar sobre as possíveis relações ou não-relações estabelecidas entre título e obra de arte.

A realidade sempre se apresentava, segundo Magritte (2009), de maneira problemática e o seu intuito era construir, por meio dos quadros, resoluções para esses problemas, propondo relações entre os objetos que tentavam sanar essas questões que a banalidade das coisas poderia esconder. Nesse sentido, Magritte propunha um deslocamento partindo das instâncias mais ordinárias até chegar a algo misterioso, através de provocações daquilo que pudesse causar estranhamento, muitas vezes, estabelecendo proximidades com o sentido freudiano da sensação Unheimlich, deslocando, assim, a trivialidade da realidade para o âmbito do fantástico.

Sobre o processo de encontrar títulos para suas telas, Magritte (2009) traçou precisas colocações: ele considera que as palavras componentes de um título estão muito distantes de se resumirem a simples explicações daquilo que se vê, assim como essas imagens tampouco teriam a função de ilustrar seus títulos. A composição da nomenclatura de seus quadros aparece no sentido de buscar características imanentes aos objetos que normalmente a consciência 
ignora, mas que se fazem presentes por fatores que, muitas vezes, mostram-se misteriosos. Nesse sentido, Magritte (2009) indica que os melhores títulos para seus quadros são os de caráter poético; estes abarcariam sentimentos que podemos ter ao olhar para as telas, encantando e surpreendendo nosso olhar e percepção, ao invés de corresponder ao simples reducionismo das sensações.

É possível encontrar um caminho que auxilia na compreensão dessa poética tão valorizada por Magritte (2009) - sobretudo, acerca dos títulos de suas pinturas - nas investigações feitas por Luigi Pareyson (2001), por exemplo. Discutindo Os Problemas da estética, o filósofo italiano discerne as complexidades que podem permear o entendimento sobre a estética, dedicandose em determinado momento ao esclarecimento sobre a poética. Para Magritte (2010), o sentido poético diz respeito tanto ao sentido equiparável ao sublime da poesia (escrita e, no caso do pintor, também visual), como sobre as nuanças experimentadas na relação que a obra de arte estabelece com seu espectador. Contudo, desde o início de seus escritos da década de 1920, observamos o pintor declarar que é impossível se alienar às suas próprias afecções na produção de seu trabalho. Pode-se entender que aí se inscreve - tanto na relação artista-obra como na relação obra-espectador (e, por que não, artista-obra-espectador?) um lampejo poético que, na intenção de uma eficácia, "se adere à espiritualidade do artista e traduz seu gosto em termos normativos e operativos"; dessa maneira, a poética de uma obra se produz intrinsecamente à subjetividade e ao contexto de quem a percebe, "pois somente nele se realiza aquela aderência e, por isso, se opera aquela eficácia" (Pareyson, 2001, p. 18).

Notam-se possíveis ressonâncias dessa condição poética quando Magritte (2009) discorre sobre quadros como L'Empire des lumières (Magritte, 1954) por exemplo. Ao produzir esse trabalho, sua intenção foi a de tornar visíveis suas ideias mais estimulantes, colocá-las nas telas para que outros também pudessem olhá-las, condizendo com sua vontade em retratar seu gosto tanto pelo dia como pela noite sem optar por nenhum deles especificamente - eis aí uma manifestação de suas emoções estéticas traduzida em imagem, as quais receberam um título de igual potencialidade poética.

\section{RESULTADOS E DISCUSSÃO}

Nas obras de Magritte, o uso das palavras ultrapassa o limite dos títulos na medida em que o artista as utiliza como pintura. Essa mistura aparece com intuito de provocar as sensações de quem observa suas obras e de questionar a realidade como é dada. Magritte, por vezes, pinta palavras que complementam ou, então, que subvertem a suposta afirmação da realidade das imagens encontradas em seus quadros. De acordo com Panek (2006), Magritte age de forma a explorar o uso de imagens visuais vinculadas a palavras, jogando com "a 
sedução na liberdade das associações construídas quando brinca com o sentido das coisas. Palavra e imagem não agem separadamente" (Panek, 2006, p. 106).

Nesse sentido, o processo de titulação utilizado por Magritte implicava, além de uma produção coletiva (comum no movimento surrealista), a escrita de microtextos que possuíam antes a intenção de produzir uma inquietação equiparável àquela que o pintor buscava quando pintava. Muito além de explicar ou descrever, esses títulos aparecem com uma pretensão ainda mais rudimentar: a de corresponder a sensações em quem os apreende: "dito de outra forma, um título (deve ser) compatível com a emoção mais ou menos viva que sentimos quando olhamos para um quadro" (Magritte, 2010, p. 229, tradução nossa), fazendo parte assim de toda a poética relativa à sua pintura.

A nosso ver, o auge desse choque entre representação e coisa aparece em La Trahison des images (Magritte, 1929a), em que se vê a imagem de um cachimbo e logo abaixo a negação da realidade desse objeto através da escrita: ceci n'est pas une pipe (isto não é um cachimbo). O título da tela nos convida então a voltar o olhar para as capacidades traiçoeiras que as imagens possuem e, além disso, o jogo da representação está de tal forma imbricado que até mesmo a técnica utilizada por Magritte nessa reprodução evidencia a constituição física do quadro, para além da imagem; ele faz uso de uma técnica chamada "impasto", em que a tinta é deixada no quadro de forma a explorar as possibilidades de textura que ela pode tomar (Helfenstein \& Elliott, 2013), causando uma outra alternativa de distinção entre a figura e as palavras, cuidadosamente pintadas, e o fundo bruto do quadro. Afinal, seriam textos ou pinturas? Pode-se esboçar uma possível resposta com o seguinte excerto:

De inúmeras formas, Magritte incorporou escritos ao ato de pintar como uma maneira de desconstruir e redefinir imagem e linguagem, em uma tentativa de provocar o problema da representação. Negando conferir um papel subordinado seja à escrita ou à representação visual e, ao invés de usar a linguagem e a imagem para romper uma da outra, derrubando a lógica, Magritte evoca o potencial revolucionário de ambas (Helfenstein \& Elliot, 2013, p. 76, tradução nossa).

Segundo Marianne Jakobi (2006), os surrealistas inauguraram um tipo de produção de títulos bem aos moldes das premissas do movimento, seguindo os métodos do automatismo psíquico e da produção coletiva. Aqui Magritte exemplifica, através do quadro, seu ponto de vista acerca da poética dos títulos, mostrando o que melhor se ajustaria a seus quadros e declarando de quebra sua crítica de como as imagens podem ser tomadas com o caráter de verdade quando não passam simplesmente de representações.

De acordo com a análise cuidadosamente feita por Michel Foucault (2008) sobre esse trabalho de Magritte, a problemática não se inscreve somente na simples conclusão de que a imagem do cachimbo não é realmente o objeto em si, evidenciada pela enunciação encontrada logo abaixo da imagem. Em se 
tratando de uma pintura, este fato já implica a noção de que a imagem representada não é exatamente a coisa em si, embora, no senso comum, haja o costume de se dizer que os desenhos são realmente aquilo que representam. Foucault (2008) aprofunda sua investigação encarando toda a composição do quadro como um caligrama, inicialmente construído com a única finalidade posterior de ser desconstruído, e que, por definição, tem "um tríplice papel: compensar o alfabeto; repetir sem o recurso da retórica; prender as coisas na armadilha da dupla grafia" (Foucault, 2008, p. 22), onde, então, não somente a imagem do cachimbo é um desenho, mas as palavras encontradas abaixo dele também o são. Inscreve-se assim uma dupla representação: a de objeto e a de palavra justapostas. O caligrama se constitui, então, como recurso cuja finalidade é dar cabo às impressões que já são vistas na representação da imagem, de forma a "apagar ludicamente" relações de oposição inerentes à percepção humana: "mostrar e nomear; figurar e dizer; reproduzir e articular; imitar e significar; olhar e ler" (Foucault, 2008, p. 23). Dessa maneira, a negação da imagem representada no quadro de Magritte vai além de uma simples relação que já está implícita na percepção dessa obra; o artista se utiliza de mecanismos que, através da tautologia do caligrama, questionam a realidade das coisas atribuindo uma concepção muito bem engendrada sobre a banalidade da realidade.

Com efeito, a representação em uma pintura, por mais real que aparente ser, pode provocar confusões na percepção. Essa tela de Magritte nos leva a enxergar um objeto que, na verdade, não está lá. A inquietação é causada justamente pelo caráter traiçoeiro que a pintura pode ter. Afinal, uma pintura não seria a coisa em si, mas somente sua representação ilusionística. Eis aí uma importante potencialidade da arte: a capacidade de provocar a libertação dos sentidos fixos e aparentes da realidade. Nessa premissa, a temática surrealista possui ainda mais aproximações com áreas onde as representações perdem seus níveis de fixidez, sendo elas: "o maravilhoso, o sonho e o inconsciente", lugares onde a mutação e a metamorfose, além da condensação, estariam muito presentes (Bradley, 2004, p. 41).

O conjunto de questões que envolvem a representatividade nas obras de arte, nesse sentido, se estrutura de forma a apontar para um caminho que não se basta simplesmente no mimetismo das formas tomadas pela realidade, mas se constitui também como um modo de visão que aumenta as possibilidades de se pensar o mundo exterior. A imaginação, ao mesmo tempo que se aproxima do mundo pela inscrição da vida no corpo com as marcas da realidade, pela sistemática de um olhar que se faria habituado à realidade aparente, portanto instaurador de relações de semelhança e similitude, se distancia porque o quadro oferece, segundo o filósofo Maurice Merleau-Ponty (2004), somente ao olhar e não ao espirito a capacidade de "repensar as relações constitutivas das coisas", 
traçando o entalhe da "textura imaginária do real". Assim, o "imaginário está muito mais perto e muito mais longe" daquilo que se apresenta (p. 22).

\section{Implicação poética do olhar}

$\mathrm{Na}$ experiência da recepção estética, em consonância com o pensamento psicanalítico, a dedicação de um olhar sensível para a obra de arte se inscreve tal como o ouvido atento do analista. Nessa medida, instala-se a concepção de criar uma relação entre obra e espectador tal como a existente entre paciente e analista, constituindo nesses moldes um olhar que se apresenta de tal forma equiparado à escuta psicanalítica (Dionisio, 2012). Contudo, os papeis atribuídos a essas relações entre psicanálise e reflexão estética estão sujeitos à mobilidade. Desse modo, é interessante pensar de que forma se inscreve a relação do olhar entre espectador e obra de arte, já que ora o sujeito pode ser o observador e ora a obra de arte, por suas provocações intrínsecas, ser quem nos olha. Essa ideia de reciprocidade da relação do olhar é explorada por Merleau-Ponty (2004), em $O$ olho e o espirito, e mais contemporaneamente pelo filósofo francês Georges Didi-Huberman (1998), em O que vemos, o que nos olha, no qual se dedicou a explorar o que pode estar presente na inscrição do espaço entre aquilo que olha e aquilo que é visto que olha e aquilo que é visto. A nosso ver, são questionamentos como esses que podem nortear um possível entendimento daquilo que demonstra Magritte através de seus quadros, sobretudo nos quais a temática do olhar está inevitavelmente empregada.

Um exemplo que chama a atenção, dessa vez por um aspecto peculiar do estranhamento, é Le Portrait (Magritte, 1935). Aqui, os objetos representados têm caráter puramente banal e caracterizariam uma simples refeição, não fosse um detalhe: um olho, posicionado ao centro do alimento, se abre, observando serenamente aqueles que olham para o quadro, eis aí o estranhamento. Seria possível inscrever aqui alguns questionamentos como, por exemplo, em que medida estamos reduzidos a espelhamentos de nossos hábitos diários? Como essas ações guardam traços de nós mesmos? A existência humana estaria atrelada às representações das ações corriqueiras que desenvolvemos de maneira quase automática? Não cabe a nós responder, mas somente atentar para as sensações que podem ser desencadeadas pelo estranhamento de um detalhe quase anódino.

É interessante notar que Magritte dá a esse quadro o título que pode ser traduzido como $O$ retrato. De acordo com Merleau-Ponty (2004), muitos pintores possuem um interesse quase mágico nas imagens produzidas por espelhos e trabalham essas perspectivas em suas obras, seja por meio de autorretratos ou então por objetos que os representem como parte pelo todo. Diante dessa imagem especular, é possível inferir como outros sujeitos também poderiam tomar as mesmas potencialidades especulares que os objetos: "o homem é espelho para o homem" (Merleau-Ponty, 2004, p. 27). O interesse dos artistas 
em imagens especulares se revela também na possibilidade de um esfumaçamento das tensões do olhar, entre quem vê e quem é olhado; um espelho possibilita, no caso dos autorretratos, que o artista seja visto ao mesmo tempo em que olha. Algo que configura a inscrição mais emblemática para os pintores, aumentando potencialmente as capacidades da visão. Nesse sentido, o filósofo declara:

O espelho aparece porque sou vidente-visível, porque há uma reflexividade do sensível, que ele traduz e duplica. Por ele, meu exterior se completa, tudo o que tenho de mais secreto passa por esse rosto, por esse plano fechado que meu reflexo na água já fazia suspeitar (Merleau-Ponty, 2004, pp. 26-27, grifos do autor).

Outro quadro, o qual pode se estabelecer como um dos seus mais enigmáticos, apresenta a imagem bem aproximada de um olho. Essa figura, representada tão de perto, evidencia um aspecto interessante: a íris desse olho se mostra como um céu cheio de nuvens. Para essa tela, Magritte (1929b) dá o título de Le Faux miroir, o que se faz engendrar a problemática do engodo provocado pelas imagens (representativas e falsamente especulares) de um quadro, mas também amplia o sentido para aquilo que se posiciona atrás de nossa visão, interferindo de maneira positiva ou negativa na percepção daquilo que vemos.

A duplicação que se apresenta em uma imagem especular ganha estatuto de imaginária no que se refere à sua construção. A imagem ali refletida figurativamente possui caráter identificatório com quem a olha de acordo com sua própria subjetividade. Dessa maneira, Merleau-Ponty (2004), argumenta que a ação dos pintores delega à visão um estatuto de magia. Isso pelo fato de eles permitirem que seu espírito saia através de seus olhos e vague por entre suas reproduções artísticas, levando em consideração todos os encadeamentos que o mundo produziu em sua subjetividade, todas as formas que a realidade pode Ihes ter tocado intimamente, a fim de se inscrever um ímpeto a produzir uma pintura "porque o mundo, ao menos uma vez, gravou dentro deles as cifras do visível" (Merleau-Ponty, 2004, p. 24).

Segundo a premissa de que nos relacionamos com uma obra através da percepção visual, a abertura de nossa visão para o mundo somente se efetiva enquanto esse mundo ao redor também nos olha de volta. Trata-se de um olhar intrapsíquico, capaz de formar imagens subjetivas em nossa percepção, produzindo cortes na realidade e criando relações inquietantes entre interior e exterior, ou seja, esse olhar transitório pode evidenciar um vazio imanente à condição humana (Dionisio, 2012).

O vazio subjetivo pode ser entendido como as próprias cavidades oculares a serem preenchidas com as potencialidades do mundo externo que se revela quando o olhar é lançado. Dessa forma, olhar pode nos remeter a uma relação de implicação entre a subjetividade de quem vê e as apresentações da realidade 
externa (Dionisio, 2012). Segundo tal ideia o olhar perspicaz e atento às potencialidades do mundo se consolida, pura e simplesmente, através da própria experiência do visível. Sendo assim, Merleau-Ponty (2004) alega:

O olho vê o mundo e o que falta ao mundo para ser quadro, e o que falta ao quadro para ser ele próprio, e, na paleta, a cor que o quadro espera; e vê, uma vez feito, o quadro que responde a todas essas faltas, e vê os quadros dos outros, as respostas outras e outras respostas (2004, p. 23).

Desse modo, portanto, Merleau-Ponty (2004), amparando-se em artistas como Paul Klee e Max Ernst, defende a tese de que há uma inversão de papeis entre os olhares: quem olha quem na relação obra-sujeito? Nas obras de arte, a questão do olhar está ainda atrelada a um viés de abertura das potencialidades visuais no caminho de busca por uma organização do visível, um reconhecimento que se dá com o apoio na dimensão pulsional. O olhar lançado a um trabalho artístico está sujeito às diversas possibilidades de relação que atravessam a subjetividade de um indivíduo. Assim, a relação entre espectador e obra seria capaz de dar visibilidade aos sentimentos mais intrínsecos dos seres humanos, já que, em psicanálise, a dimensão do olhar implica muito mais do que simplesmente ver através dos olhos, de modo a elevar a percepção até âmbitos exponencialmente intra-subjetivos (Dionisio, 2012).

De acordo com esse pensamento, o olhar dedicado à reflexão estética traria consigo características da pulsão escópica, perpassando por três momentos: no primeiro, se inscreve o ímpeto a direcionar o olhar ao objeto, ao outro; logo em seguida, esse exterior se converte em si mesmo, assim o vislumbre volta-se para o próprio sujeito e o momento final dessa relação acontece quando aquele que olha converte-se em aquele que é visto (Dionisio, 2012).

É possível inscrever nessa linha de raciocínio as problemáticas elencadas por Magritte acerca da relação visual estabelecida entre a realidade e os indivíduos, bem como a provocação de desestabilizar a percepção dos espectadores no que diz respeito a metamorfosear características essenciais aos elementos cotidianos para instâncias que podem causar estranhamento, através de imagens de situações corriqueiras, como em Le portrait (Magritte, 1935), onde uma refeição, por exemplo, pode espelhar todo um processo identificatório; ou então em Le Faux miroir (Magritte, 1929b), que como foi sugerido, poderia jogar com a questão das obras serem falsos espelhos para aqueles que as observam, constituindo-se de maneira a refletir instâncias subjetivas de seus espectadores, além de questionar as diversas maneiras de como os sujeitos artistas ou espectadores - se relacionam com a realidade das obras de arte.

\section{O duplo na imagem; estranhamento na obra de Magritte}

Por volta de 1926 e 1927, Magritte produziu algumas obras em que explora a temática da duplicação. Alguns exemplos são os quadros La Fin des 
contemplations (Magritte, 1927a) e Le Double secret (Magritte, 1927b). As imagens aqui representadas se duplicam possivelmente com a finalidade de caracterizar um corte na individualidade das figuras humanas retratadas, que quando são posicionadas lado a lado, como o pintor faz, criam uma certa inquietude, produzindo um estranhamento de si mesmo.

Em Le Double secret (Magritte, 1927b), vemos a utilização de um corte com a finalidade de duplicação. Com um talho que beira a brutalidade, vemos 0 rosto da figura representada deslocado para o lado esquerdo. Ao ocorrer essa duplicação, o corpo humano aparenta ser feito de um material sensível, possível de ser rasgado como uma folha de papel, proporcionando que vejamos um interior quase vazio, a não ser pela presença de pequenas esferas que lembram guizos - objeto muito recorrente em outras obras de Magritte -, deixando a impressão de que o corpo humano não passa de uma carcaça muito frágil.

Uma outra observação permite pensar que a cor utilizada por Magritte nos olhos da figura pode fazer referência ao mar aberto que vemos como paisagem de fundo, em contraste com a parede desbotada à direita da tela. O título dado à obra nos instiga a questionar o que seria esse duplo segredo e como poderia ser desvelado, se é que isso seria possível. Com base no oceano ao fundo, juntamente à coloração dos olhos da pessoa e as implicações do corte produzido por Magritte nessa figura, é possível constituir certas referências ao conceito de sentimento oceânico que aparece na obra de Freud (1930/2014), O mal-estar na civilização.

Inicialmente, esse termo surgiu nas conversas de Freud (1930/2014) com um amigo, quando eles discutem sobre o que levaria as pessoas à procura da religião. Enquanto Freud (1930/2014) argumenta que entende a religião como uma ilusão, este amigo apresenta suas concepções sobre um movimento que leva as pessoas a buscar algo grandioso, que tivesse capacidades incomensuráveis. O psicanalista, então, se dedica a aprofundar sua pesquisa para descobrir de onde viria esse sentimento de tão vastas proporções.

Suas investigações se iniciam pela compreensão de que um sentimento tão abrangente não poderia aparecer a partir do exterior, mas do mundo intrapsíquico. Visto que as fronteiras do Eu para o mundo externo, ao menos na vida adulta, parecem muito bem delimitadas no indivíduo que se difere de outros, Freud (1930/2014) indica, então, que o prolongamento dessa instância incomensurável se daria em direção ao plano interno; ora, essa extensão do Eu se inscreveria no âmbito do inconsciente, lugar em que as fronteiras não aparecem nitidamente.

Nos estudos desenvolvidos por Freud (1930/2014) sobre onde teriam surgimento essas impressões entre instâncias externas e internas, o psicanalista argumenta que talvez esses sentimentos não sejam estáveis durante toda a vida do sujeito e que possam ter passado por um processo evolutivo, tendo uma origem distinta da forma como se manifestam na vida adulta. Para ele, durante 
um tempo primário de formação subjetiva, os bebês ainda não discernem completamente aquilo que faz parte de um mundo interno e o que seria externo a eles. Essa apreensão começa a se inscrever, segundo o autor, através dos diversos estímulos a que essa criança estaria exposta, bem como por meio das sensações que lhe causariam sentimentos ruins e desagradáveis. No entanto essa diferenciação tão dura tende a ser maleabilizada no decorrer do processo de subjetivação e na evolução da percepção do mundo, assim:

\begin{abstract}
Algumas coisas a que não se gostaria de renunciar, por darem prazer, não são Eu, são objeto, e alguns tormentos que se pretende expulsar revelam-se como inseparáveis do Eu, de procedência interna. Chega-se ao procedimento que permite, pela orientação intencional da atividade dos sentidos e ação muscular apropriada, distinguir entre o que é interior - pertencente ao Eu e o que é exterior - oriundo de um mundo externo -, e com isso se dá o primeiro passo para a instauração do princípio da realidade, que deve dominar a evolução posterior (Freud, 1930/2014, pp. 18-19).
\end{abstract}

A expressão vaga da pessoa representada por Magritte (1927b) em Le Double secret pode ser vista talvez como a conscientização de um certo vazio interior ou de uma possível incompletude: "seus conteúdos ideativos seriam justamente os da ausência de limites e da ligação com o todo" (Freud, 1930/2014, p. 19). De acordo com Umland (2013), esse deslocamento através da duplicação da imagem de si mesmo pode caracterizar uma crise de identidade, em que as significações constituintes do indivíduo não seriam rígidas e fixas como se costuma presumir. Desse modo, há a possibilidade de concluir que, através da cisão e da duplicidade, os ideais identitários se tornariam, em última instância, transmutáveis.

Outro intrigante quadro produzido por Magritte, ainda sobre a temática do duplo é La Fin des contemplations (Magritte, 1927a). Neste trabalho vemos a duplicidade de um personagem posicionado de perfil que, como em Le Double secret (Magritte, 1927b), tem um rasgo que vai desde cima de seus olhos até seu peito, que é onde o limite físico da tela nos permite ver, também passando a impressão do corpo humano ser frágil e facilmente dilacerável. A paisagem de fundo também se duplica, além de possuir igualmente um rasgo que revela um fundo branco. As duas reproduções nesse quadro são, aparentemente, iguais; no entanto, após uma análise minuciosa, conclui-se que os lados da tela guardam leves diferenças entre si, pequenos detalhes que tornam este trabalho ainda mais inquietante. Além disso, o título da obra nos leva a exigir um esforço a mais de nosso olhar, procurando por detalhes escondidos nas representações, em que buscaríamos incessantemente um fim para nossas contemplações.

A questão da duplicidade na obra de Magritte pode suscitar relações com o conceito freudiano sobre o duplo, encontrado como desdobramento da teoria de Freud acerca do Unheimlich (o estranho). De acordo com Umland (2013, p. 37), a tradução literal do termo francês se dédoubler seria "dividir-se em duas 
partes"; nesse sentido, a autora busca referência na psicanálise e diz que essa cisão corresponde a uma divisão da personalidade. Ela propõe, amparando-se na teoria freudiana, que a duplicação vista nestes quadros de Magritte evidencia aquilo que, por mais familiar que seja, pode causar um estranhamento através de seu duplo, trazendo à tona o que deveria ter permanecido escondido (Umland, 2013; Schelling citado por Freud, 1919/1996). No entanto, cabe aqui um esclarecimento acerca do conceito de divisão (splitting) da personalidade empregado por Umland (2013). A ideia de um sentimento que divida o Eu, separando uma parte crítica de um resto de Eu, estaria em consonância com a psicologia do Ego e não de acordo com as descobertas psicanalíticas acerca de uma separação daquilo que estaria no Inconsciente e aquilo que viria à tona como conteúdo manifesto.

Analisando o conto "O Homem da Areia" de E. T. A. Hoffmann, Freud (1919/1996) se depara com o aparecimento do duplo, onde características físicas, psíquicas ou comportamentais, ou seja, singulares em uma pessoa possuem certa ligação com as de outra, tornando esses sujeitos idênticos. Em outras palavras, esses traços seriam tão marcadamente semelhantes que o sujeito pode chegar a se confundir sobre o que constitui seu verdadeiro Eu. $O$ que marca essa duplicidade das singularidades, na visão do psicanalista, é o encontro de certas repetições dessas peculiaridades: idiossincrasias e construções particulares, imanentes à vida de um determinado sujeito, se apresentariam então curiosamente identificáveis em uma outra pessoa.

O olhar de Freud para as obras de arte nesse ponto de sua carreira - em 1919 - se debruça sobre aspectos que os estetas e críticos de arte, até então, normalmente não consideravam como dignos de análises, onde seria, de maneira geral, somente através do belo e do sublime que uma obra atingiria suas potencialidades artísticas. Nesse sentido, o psicanalista versa sobre a capacidade que a estética tem de provocar estranhas inquietações, dedicando-se assim a observar antes a intensidade desses sentimentos produzidos pela arte, do que Ihes reduzir a características referentes a um tipo específico de interesse. Dessa forma surgem acepções distintas daquelas reduzidas a um único ideal estético, chegando a produzir sentimentos com teor bizarro e exótico (Dionisio, 2012).

As conclusões de Freud sugerem que, com a evolução do narcisismo primário, a tendência é de que a presença do "duplo" não se desintegre por completo, restando características que, em certa instância, possuem a função de promover a autocrítica do sujeito. É como se, com base em aspectos que poderiam se tornar reconhecíveis a si mesmo, vistos em outros indivíduos, esse senso de crítica despertasse à consciência certos tipos de censura intrapsíquica, com funções críticas vindas da auto-observação.

$\mathrm{O}$ fato de que existe uma atividade dessa natureza, que pode tratar o resto do ego como um objeto - isto é, o fato de que o homem é capaz de auto-observação - torna possível investir a velha ideia de 
'duplo' de um novo significado e atribuir-Ihe uma série de coisas sobretudo aquelas coisas que, para a autocrítica, parecem pertencer ao antigo narcisismo superado dos primeiros anos (Freud, 1919/1996, p. 294).

Dessa perspectiva, pode-se inferir que o sentimento que aparece frente a essa imagem duplicada de si mesmo seja muito próprio à lógica da primeira tópica freudiana, em que a dualidade se inscreve entre os âmbitos do inconsciente e consciente, de modo a residir "aí o primeiro duplo que causa estranhamento: o outro de nós mesmos" (Dionisio, 2012, p. 208). Há, portanto, uma forte inquietação frente ao fato de reconhecer em um outro uma instância tão intimamente ligada ao si mesmo que, justamente por essa razão, provoca estranhamento.

De acordo com Gustavo Dionisio (2012), as concepções acima anunciadas na teoria freudiana fazem referência ao que Lacan chamou de "extimité" - uma instância exteriorizada daquilo que é "íntimo" - sugerindo que, se houve identificação naquilo que causou inquietação em um âmbito externo, seria por existir uma afinidade equivalente interna, podendo corresponder à identificação projetiva. Sendo este sentimento uma interlocução entre as instâncias interna e externa, seu desdobramento acarreta em uma possibilidade de individualização através do discernimento e compreensão da autoimagem, algo essencial aos modos de subjetivação e reconhecimento de si como Eu (Dolar, 1992; Dionisio, 2012), de forma que "o primeiro discernimento do fenômeno Unheimlich é a ação de um reconhecimento" (Dionisio, 2012, p. 208).

Freud (1919/1996) mostra ainda que a sensação de estranhamento causada pela duplicação da imagem de si, em certas circunstâncias, pode remeter à esfera do onírico, sendo esta outra possível relação com uma temática bastante recorrente às obras de Magritte. Um interessante exemplo, evidenciado pela autora Francina de Sousa (2007), do conceito de estranhamento nas artes, especificamente na literatura, se dá reconhecidamente na obra "A Metamorfose", de Kafka:

A literatura do referido autor trata do absurdo dando-Ihe um caráter tão ordinário que nos causa estranhamento e mal-estar. O fato de Gregor Samsa perceber-se metamorfoseado em barata é desenvolvido ao longo da história como algo passível de realmente acontecer, com um realismo assustador. Observa-se que Kafka não se utiliza de elementos que nos levem a acreditar tratar-se de uma fábula ou coisa do tipo, pelo contrário (Sousa, 2007, p. 22).

Embora Kafka não seja evidentemente surrealista, essa imagem demonstra uma concepção que o movimento já possuía como pressuposto na época de sua criação: a intencionalidade de provocar, através da arte, um deslocamento para instâncias desconhecidas, mas que mantém um ponto de referência na realidade que pode ser entendida como banal. A crítica surrealista se inscreve, portanto, no sentido de um posicionamento negativo ao ordinário, indo aos limites do inexplicável, em que se torna possível atingir algo que "foi 
recalcado pela sociedade, mas pela via estética, tem possibilidade de vir à luz" (Sousa, 2007, p. 22).

\section{CONSIDERAÇÕES FINAIS}

Nesse trabalho buscamos recuperar certos aspectos da vida e obra de René Magritte sob a ótica da teoria psicanalítica, ensaiando com isso trazer uma contribuição para sua fortuna crítica em consonância ao pensamento freudiano. Para se compreender as várias concepções do pintor sobre a arte de pintar, o sentido da arte, e o processo de construção de um quadro, bem como a criação de seu título, e o entendimento sobre um pensamento poético intrínseco às suas ideias, utilizamos os escritos produzidos por ele como suporte para a análise.

Almejamos apresentar aproximações entre a obra de Magritte e a teoria psicanalítica, tendo como pressuposto o olhar inaugurado por Freud (1914/2013) em seu texto sobre O Moisés de Michelangelo, com o qual nos trouxe um significativo ensaio sobre as implicações imanentes à construção dessa obra de arte, evitando a aplicação dos conceitos da teoria psicanalítica à escultura em questão. Buscamos, portanto, aquilo que estaria "na filigrana" da construção das pinturas desse importante pintor, e o que pode se revelar com um olhar mais atento aos detalhes dessas construções. Com o desenvolvimento de nossas pesquisas, foi possível observar a singularidade intrínseca à produção de cada obra em particular; assim, pudemos versar sobre o processo de criação desses quadros junto à concepção de seus títulos, os atravessamentos que as telas possuem, as influências que Magritte teve e que podem aparecer em suas produções, os questionamentos que tanto motivaram o pintor a produzir outras realidades através de seu trabalho, e suas concepções poéticas da realidade traduzidas por meio de tintas em suas telas. Também procuramos apontar certas aproximações temáticas recorrentes no trabalho de Magritte - por exemplo, o duplo, representação, sonhos, estranhamento do cotidiano - com concepções da teoria psicanalítica, às quais dizem respeito aos modos de subjetivação implicados tanto na relação entre o artista e a obra, como entre a obra e o espectador.

Nos trabalhos em que Magritte explora o tema do duplo, La Fin des contemplations (Magritte, 1927a) e Le Double secret (Magritte, 1927b), do mesmo ano, revelam-se possíveis correspondências com a teoria freudiana, especificamente, em momentos nos quais o criador da psicanálise discorre sobre as configurações internas e externas do Eu referentes ao "sentimento oceânico", fazendo o indivíduo se deparar com algo Umheimlich em seu dia a dia: o encontro com a duplicação da própria imagem do sujeito, fazendo balizar elementos inconscientes, trazendo à tona aquilo que deveria ter permanecido escondido, algo que de tão familiar, se tornou estranho. Dessa maneira, através da metaforização visual dos objetos, as produções de Magritte convergem para a 
descoberta de novos sentidos poéticos imanentes ao cotidiano, despertando o olhar para relações outras de afinidade, presentes entre esses objetos e suas inúmeras possibilidades de representação (Draguet \& Goormans, 2013).

Através da construção dos quadros, Magritte empenhava-se em realizar um pensamento visível. Por meio daquilo que o tocava de maneira sensível, ele produzia suas telas e encontrava um sentido poético na realidade que se apresentava aos seus olhos. A desestabilização que Magritte provoca ao olhar que se lança às suas obras pode se tornar mais evidente nas telas em que o pintor emprega, exatamente, a representação dos órgãos responsáveis pela visão. Na série de obras que selecionamos para edificar as análises referentes à temática do olhar, composta pelos quadros Le Portrait (Magritte, 1935) e Le Faux miroir (Magritte, 1929b) foi possível apresentar uma leitura que versa sobre como a relação entre espectador e obra de arte se estabelece tendo por meio de contato o olhar. Além disso, procuramos aproximar o pensamento clínico psicanalítico e a reflexão estética através dessa ligação entre obra e sujeito, atentando-nos para as inquietações que se inscreveriam no estabelecimento dessa relação, que, em boa medida, se configura como transferencial.

\section{DECLARAÇÃO DE CONFLITOS DE INTERESSE}

Os autores declaram não haver conflitos de interesse.

\section{REFERÊNCIAS}

Breton, A. (1985). Manifestos do Surrealismo. São Paulo, SP: Editora Brasiliense. Bradley, F. (2001). Surrealismo. São Paulo, SP: Cosac Naify.

Didi-Huberman, G. (1998) O que vemos, o que nos olha. São Paulo, SP: Ed. 34.

Dionisio, G. H. (2012). Pede-se abrir os olhos: Psicanálise e reflexão estética hoje. São Paulo, SP: Annablume.

Dolar, M. (1992) "I shall be with you on your wedding-night": Lacan and the Uncanny. October, 58, 5-23. doi: 10.2307/778795

Draguet, M., \& Goormans, C. (2013). Once the image is isolated. What happens to the mind? In A. Umland (Ed.), Magritte: The Mystery of the Ordinary, 1926-1938 (pp. 26-42). Nova York, NY: The Museum of Modern Art.

Freud, S. (1996). O "Estranho". In Edição Standard Brasileira das Obras Psicológicas Completas de Sigmund Freud (Vol. 17, pp. 233-270). Rio de Janeiro, RJ: Imago. (Trabalho original publicado em 1919).

Freud, S. (2013). Moisés de Michelangelo. In Edição Standard Brasileira das Obras Psicológicas Completas de Sigmund Freud (Vol. 11, pp. 373-412). São Paulo, SP: Companhia das Letras. (Trabalho original publicado em 1914). 
Freud, S. (1930/2014). O mal-estar na civilização. In Edição Standard Brasileira das Obras Psicológicas Completas de Sigmund Freud (Vol. 18, pp. 13122). São Paulo, SP: Companhia das Letras. (Trabalho original publicado em 1914).

Foucault, M. (2008). Isto não é um cachimbo. Rio de Janeiro, RJ: Paz e terra.

Gablik, S. (1985). Magritte. London: Thames and Hudson.

Helfenstein, J., \& Elliott, C. (2013). A lightning flash is smoldering beneath the bowler hats. In A. Umland (Ed.), Magritte: The Mystery of the Ordinary (pp. 70-88). Nova York, NY: The Museum of Modern Art.

Jakobi, M. (2006). Jean Dubuffet et la fabrique du titre. Paris: CNRS Éditions.

Magritte, R. (1927a). La Fin des contemplations. Private collection. Recuperado de: https://www.menil.org/collection/objects/2329-an-end-tocontemplation-la-fin-des-contemplations

Magritte, R. (1927b). Le Double secret. Chicago, Art Institute of Chicago. Recuperado de: https://www.artsy.net/artwork/rene-magritte-thesecret-double-le-double-secret

Magritte, R. (1929a). La Trahison des images. Los Angeles, Los Angeles County Museum of Art. Recuperado de: https://collections.lacma.org/node/239578

Magritte, R. (1929b). Le Faux miroir. New York, Museum of Modern Art. Recuperado de: https://www.moma.org/explore/multimedia/audios/378/6536

Magritte, R. (1935). Le Portrait. New York, Museum of Modern Art. Recuperado de: https://www.moma.org/collection/works/79990?locale=en

Magritte R. (1954). L'Empire des lumières. Brussels, Musées Royaux des BeauxArts de Belgique Recuperado de: https://www.fine-arts-museum.be/fr/lacollection/rene-magritte-lempire-des-lumieres

Magritte, R. (2009). Écrits completes. France: Flammarion.

Magritte, R. (2010). Escritos. Madrid: Sintesis.

Merleau-Ponty, M. (2004). O olho e o espírito. São Paulo, SP: Cosac Naify.

Pareyson, L. (1997). Os problemas da estética. São Paulo, SP: Martins Fontes.

Sousa, F. E. (2007). O estranho na obra de arte. Diálogos: Boletim do Ágora Instituto Lacaniano, (02), 20-23. Disponível em: http://agorainsti.dominiotemporario.com/doc/boletim_2_ano_2007[1].pd $\mathrm{f} \#$ page $=20$.

Umland, A. (2013). "This is how marvels begin". In A. Umland (Ed.). Magritte: The Mystery of the Ordinary, 1926-1938 (pp. 26-42). Nova York, NY: The Museum of Modern Art. 
Sobre os autores

Alan Ricardo Floriano Bigeli é Psicólogo graduado pela Faculdade de Ciências e Letras (Unesp), Assis, SP, Brasil. alan.rfb@gmail.com

Gustavo Henrique Dionisio é Doutor em Psicologia Social da Arte pelo Instituto de Psicologia da Universidade de São Paulo (USP). Professor de Graduação e PósGraduação no Departamento de Psicologia Clínica da Universidade Estadual Paulista Júlio de Mesquita (UNESP), Assis, SP, Brasil. gustavohdionisio@gmail.com

Certificamos que todos os autores participaram suficientemente do trabalho para tornar pública sua responsabilidade pelo conteúdo. Ambos os autores, Alan Ricardo Floriano Bigeli e Gustavo Henrique Dionísio foram responsáveis pela idealização do artigo, pela conceitualização e pela obtenção do financiamento. Alan Ricardo Floriano Bigeli realizou a pesquisa, as investigações e redação (inicial e final) do artigo. Gustavo Henrique Dionísio foi responsável pela supervisão da redação do artigo, orientação com a idealização e revisão final.

Os autores agradecem a Fundação de Amparo à Pesquisa do Estado de São Paulo (FAPESP) pelo financiamento da pesquisa.

Recebido em: 02/09/2016 $1^{\text {a }}$ revisão em: 24/01/2017 $2^{a}$ revisão em: 08/04/2017 Aceito em: 09/04/2017 